REVIEW

\title{
Radiotherapy for non-functioning pituitary adenomas
}

Kristien Boelaert and Neil J L Gittoes

Division of Medical Sciences, University of Birmingham, Queen Elizabeth Hospital, Edgbaston, Birmingham B15 2TH, UK

(Correspondence should be addressed to NJL Gittoes; Email: n.j.gittoes@bham.ac.uk)

\begin{abstract}
The initial management of large non-functioning pituitary adenomas is surgical debulking. In some cases, postoperative radiotherapy (RT) is administered in order to reduce the likelihood of tumour regrowth. Historically, there have been concerns surrounding a number of potentially significant complications of pituitary RT. Recent contributions to the literature, however, suggest that pituitary RT may be less hazardous than was originally thought. This article reviews the evidence relating to the potential side-effects of RT and weighs these risks against the clinically beneficial effects of preventing pituitary tumour regrowth.
\end{abstract}

European Journal of Endocrinology 144 569-575

\section{Introduction}

Non-functioning pituitary adenomas (NFAs) are common tumours of the anterior pituitary and are the most frequent indication for pituitary surgery. Despite extensive efforts, little is known of their pathogenesis (reviewed in 1-3). 'Clinically non-functioning pituitary adenomas' comprise a heterogeneous array of tumour subtypes that are derived from a variety of pituitary cell types $(4,5)$. The initial management of large nonfunctioning pituitary macroadenomas is surgical debulking to relieve mass effects on adjacent structures, principally the optic chiasm. With surgery alone, however, a significant proportion $(30-50 \% ; 6-12)$ of NFAs will regrow and therefore require further treatment, sometimes up to 20 years after the initial surgery. In an effort to reduce the likelihood of tumour regrowth after surgery, postoperative pituitary radiotherapy (RT) is often employed, although the necessity, efficacy and potential complications of this treatment modality are the subjects of much debate. In this review, we endeavour to subject the available literature to a critical analysis and to provide a practical approach to the use of pituitary RT in the management of patients with NFAs.

\section{Postoperative radiotherapy reduces the risk of regrowth of NFAs}

During the 1960s, pituitary surgery generated poor long-term remission/cure rates for NFAs, tumour regrowth at 10 years being noted in up to $75 \%$ of subjects $(13-16)$. These observations spurred clinicians into adopting an adjuvant mode of therapy - namely pituitary RT - in an effort to reduce the excessive rates of regrowth. The majority of subsequent studies (see Table 1) have supported a role for RT, although in none of these has RT been randomly assigned to patients. When RT has been used, there has been significant selection bias, the tendency being to reserve RT for the largest or more aggressive pituitary tumours. The limitations of these studies and the lack of any randomised controlled trials of the use of postoperative RT versus other treatment modalities have served to fuel the continuing dilemma over the role of postoperative RT in the management of patients with pituitary tumours (17).

It has been suggested that the poor results of surgery alone (performed in the 1960s) may have reflected poor surgical technique, which was often performed using a transcranial approach with unsophisticated imaging modalities. More recent studies have reassessed the efficacy of modern surgery alone to determine whether it is an effective and definitive treatment for NFAs. Data from Oxford, UK, would argue against this, however. Bradley et al. (18) described a series of 132 patients with NFAs; 98 of these patients were advised not to receive adjuvant RT. The criteria used for withholding RT were as follows: (a) the absence of radiological or surgical evidence of parapituitary invasion; (b) complete surgical removal as reported by the surgeon at the time of the operation; (c) the absence of suprasellar extension 2 months postoperatively; and (d) no evidence of histological features of aggressive tumour behaviour (mitoses or poor cellular differentiation). After 13 years of follow-up, 8 patients out of 73 showed evidence of tumour regrowth. A recent re-examination of outcomes in this cohort of patients, however, 
Table 1 Studies comparing recurrence rates of pituitary adenomas following surgery with or without RT.

\begin{tabular}{llcc}
\hline Study & Follow-up period & $\begin{array}{c}\text { Recurrence rate } \\
\text { after surgery (\%) }\end{array}$ & $\begin{array}{c}\text { Recurrence rate } \\
\text { after surgery + RT (\%) }\end{array}$ \\
\hline Ciric et al., 1983 (7) & 6 months-14 years & 28 & 6 \\
Ebersold et al., 1986 (8) & 4 years-8 years & 16 & 9 \\
Chun et al., 1988 (9) & 2 years-18 years & $19-22$ & $2-10$ \\
McCollough et al., 1991 (11) & 5 years-21 years & N/A & 5 \\
Comtois et al., 1991 (12) & 1 year-16 years & 21 & N/A \\
\hline
\end{tabular}

revealed that of the 65 patients followed, tumour recurrence was found in 21 (32\%) after a total followup period of 20 years (19). Hence, despite the employment of what appeared to be markers of a good prognosis, approximately one-third of tumours regrew when treated with surgery alone.

We have previously described the rates of regrowth of NFAs in 2 cohorts of patients who received disparate postoperative management with respect to the application of pituitary RT (6). One group $(n=63)$ was treated in a centre that routinely administered RT after initial debulking pituitary surgery, whereas the other group $(n=63)$ was treated in a unit that rarely adopted this approach. The actuarial progression-free survival was $93 \%$ at 5,10 and 15 years for patients treated with postoperative RT. In comparison, patients who did not receive RT had recurrence-free survival rates of 68,47 and $33 \%$ at 5,10 and 15 years respectively (6). We, like others, found no independent prognostic indicators of tumour regrowth other than the administration of RT in the postoperative period (20). Taken together, the data from Birmingham and Oxford show that the results of surgery alone for NFAs is poor and that administration of postoperative RT can significantly reduce the chance of tumour regrowth.

\section{Complications of radiotherapy - how significant are they?}

There is compelling evidence that RT prevents regrowth of NFAs following debulking surgery. However, over many decades a number of potentially significant complications of pituitary RT have been described; some represent justified concerns, whilst others are less well substantiated and require further analysis. The following text reviews the literature relating to the potential side-effects of RT.

The immediate side-effects of RT are mild and include nausea and lassitude that may last up to 1-2 months after treatment. Diminished taste and olfaction can last for up to 6 months. Hair loss at entry sites may persist for up to 1 year after RT (4). The more significant potential complications of RT are discussed below.

\section{Hypopituitarism}

Quantitatively, the most significant problem following RT is radiation-induced hypopituitarism that occurs as a result of direct damage to the pituitary and also secondary to hypothalamic damage, as is evidenced by appropriate pituitary responses to administration of exogenous hypothalamic releasing hormones (21-23). Up to $50 \%$ of patients develop panhypopituitarism following pituitary surgery and RT (21-24). The speed of onset is related to the total and fractional doses of RT $(21,22)$, and the incidence of hypopituitarism increases with time from exposure. Littley et al. (21) examined the incidence of hypopituitarism following RT: at 5 years after exposure, all patients were found to be growth hormone deficient, $91 \%$ were gonadotrophin deficient, $77 \%$ were corticotrophin deficient and $42 \%$ were thyrotrophin deficient. Despite the observed relative sensitivities of secretory cell types to pituitary RT, deficiency states may occur in an unpredictable sequence; thus, full endocrine testing is obligatory in all patients after pituitary RT. Furthermore, deficiency states may take up to 20 years to develop, stressing the importance of long-term follow-up for these patients $(20,22,25)$.

Table 2 Studies showing mortality rates in patients with hypopituitarism.

\begin{tabular}{lccc}
\hline Study & SMR (females) & SMR (males) $^{\mathbf{1}}$ & Overall (SMR) $^{\mathbf{1}}$ \\
\hline Rosén \& Bengtsson 1990 (28) & 2.83 & 1.45 & 1.81 \\
Bates et al., 1996 (66) & 2.29 & 1.50 & 1.73 \\
Bulow et al., 1997 (29) & 2.93 & 1.91 & 1.73 \\
Bates et al., 1999 (67) & 1.20 & 1.30 & 1.20 \\
Tomlinson et al., 2000 (26) & 2.29 & 1.57 & 1.87 \\
\hline
\end{tabular}

${ }^{1}$ SMR, standard mortality ratio. 
The implications of hypopituitarism go beyond the inconvenience of taking life-long pituitary-hormonereplacement therapy. A number of reports have confirmed that patients with hypopituitarism have significantly increased mortality (standardised mortality ratio $\sim 2$; see Table 2 ), although the precise reasons for this excess have not been fully elucidated. A recent large study has confirmed increased mortality, especially in female patients with hypopituitarism (26). Major causes of excess mortality in this cohort were circulatory, respiratory and cerebrovascular in nature - findings that were also confirmed by others (27). Uncorrected growth hormone (GH) deficiency may be a contributing factor in the excess mortality in hypopituitary patients $(28,29)$, although the doses of other pituitary hormones used in replacement therapy might also be of relevance.

The prevalence of hypopituitarism in patients treated for NFAs cannot be attributed solely to the effects of pituitary RT. A significant proportion of patients have hypopituitarism at the time of diagnosis. Tsang et al. (22) found that $20-50 \%$ of patients have varying degrees of hypopituitarism at presentation. Following RT, hypopituitarism requiring hormone replacement with thyroxine, glucocorticoid and sex hormone was noted in 65,68 and $67 \%$ of patients respectively (see Fig. 1). Radiation was reported to be a contributory cause in 23, 16 and 13\% of cases respectively. In addition, patients treated with trans-sphenoidal surgery alone have significant rates of hypopituitarism (19).

\section{Radiation-induced tumour formation}

In the early 1960s, a number of case reports of parasellar fibrosarcomas were described in patients with pituitary adenomas who received RT following pituitary surgery. X-ray treatment had previously been implicated in the development of meningiomas and gliomas in children who received scalp irradiation for conditions such as ringworm $(30,31)$. The majority of cases of intracranial tumours following pituitary RT have been published as case reports, thus making it impossible to assess the true incidence of this potential complication. Moreover, published reports are weighted towards describing the unusual, and an association may be one of ascertainment rather than causation.

In some studies, the risk of intracerebral neoplasm formation has been estimated to be as high as $1-2 \%$, sometimes occurring with a latency of 8-15 years (31-33). However, it is important to appreciate that patients with pituitary tumours represent a highly selected group of individuals who receive disproportionately frequent imaging. Thus, the incidence cannot be directly compared with that observed in the general population, and instead should be compared with those patients with pituitary tumours treated with surgery alone. It is also noteworthy that a recent study has detected a 3.9-fold excess of malignancies (albeit extracerebral neoplasms) in patients with NFAs, compared with the general population, suggesting that the incidence of tumours may be higher, irrespective of the treatment modality (34).

Jones (35) reviewed the world literature (encompassing a 22-year period) on the subject of secondary tumour formation following pituitary RT: 16 cases of meningiomas were found in irradiated patients, but 19 cases were also detected in unirradiated pituitary patients. Gliomas were present in 18 irradiated patients and in 9 patients who were not irradiated. Again, there were no available denominators to allow the true incidence of these tumours to be determined. Clearly, the data in this area are suboptimal, although there is no clear causal link between pituitary RT and

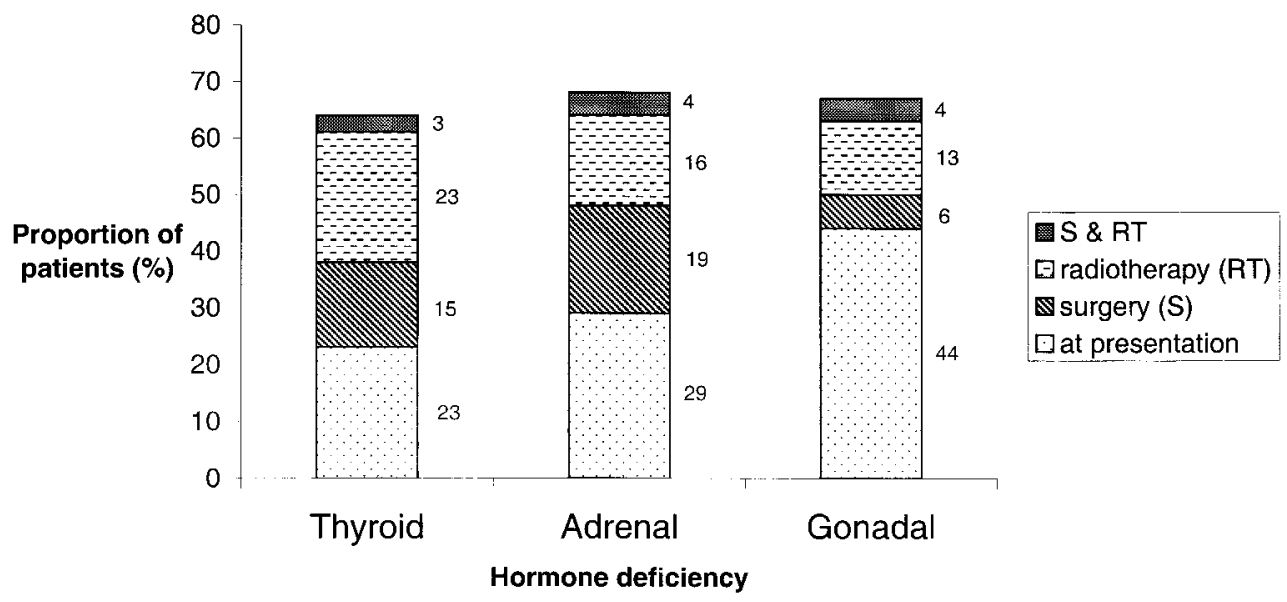

Figure 1 Proportion of patients with hypopituitarism attributable to the causes shown during follow-up for pituitary tumours. Data for thyrotrophin, adrenocorticotrophin and gonadotrophin deficiencies are shown (22). 
secondary intracranial tumours. However, there may be a common aetiological association between pituitary tumours, meningiomas and gliomas.

\section{Damage to the optic chiasm}

The optic chiasm is radiosensitive, and blindness due to RT-induced chiasmal damage has been well documented $(25,36-39)$. A $1-2 \%$ risk of radiotherapy-induced damage to the visual pathways has been quoted (40-45), with a latency of between 2 months to 4 years following irradiation $(25,37,39)$. Gadoliniumenhanced magnetic resonance imaging (MRI) scanning has been instrumental in determining the pathological basis of radiation injury to the optic chiasm; such injuries have been shown to be due to damage to the vasa nervorum $(36,38)$. The risk of chiasmal damage is directly related to the total dose administered and the dose per fraction of RT. With modern RT planning and dosing schedules, however, damage to the optic chiasm is extremely rare. Jones (30) found no cases of optic neuropathy after a 10-year follow-up of 332 patients treated with $4500 \mathrm{cGy}$ in daily doses of $180 \mathrm{cGy}$. Radiation-induced damage to the optic chiasm is of theoretical and historical interest but offers no identifiable risk when carefully planned RT is administered.

\section{Neuropsychological changes following pituitary radiotherapy}

A number of aspects of quality of life and neurocognitive function have been examined in patients following pituitary RT, though the results have been discrepant (30, 36, 46-48). A number of independent variables, such as the effects of surgery, RT, and hypopituitarism, act in concert to cloud the relative contribution of each to changes in quality of life. Furthermore, the end points in such assessments are often 'soft'. Poor social adjustment, mood disorders (including depression and memory deficits) have been reported following pituitary RT (35, 46-48). Symptoms of depression and anxiety have been found to be more prevalent in patients treated with pituitary RT than in those treated with surgery alone $(36,48)$. Others have noted greater memory deficits in patients treated with a combination of surgery and RT than in those treated with either treatment modality alone. The full impact of the neurocognitive sequelae that result from limited-field RT to the pituitary region has been inadequately studied. More research is required to determine the relative contributions of hormone deficiencies, surgery, and RT to any neurocognitive dysfunction $(36,44)$.

\section{Which tumours should be treated with pituitary radiotherapy?}

The 10-year follow-up data from our own study (6) showed that $53 \%$ of patients who were not treated with
RT showed no evidence of tumour regrowth. Furthermore, a study by Lillehei et al. (49) revealed that following radical tumour clearance (resulting in an empty sella upon postoperative MRI), the rate of tumour regrowth without RT was $6 \%$ after 5 years. These data suggest that a significant proportion of NFAs will not regrow despite the absence of RT. Ideally, therefore, a means of predicting the regrowth potential of NFAs is required to allow targeted therapy of those tumours with regrowth potential. At present, however, there are no reliable clinical (10), radiological (19), pathological (50) or molecular parameters (51-56) that predict the likelihood of tumour recurrence.

Decisions relating to the administration of RT are often made after an initial postoperative MRI scan at $4-6$ months $(6,18)$. If there is a 'significant' tumour remnant, RT is often requested, but at present there is no definition of 'significant'. We know from the Oxford data (19) that even when the tumour remnant is confined to the sella, without RT there is a $32 \%$ risk of regrowth. Data from Lillehei et al. (49) show that with no macroscopic tumour remnant on MRI, the risk of regrowth is very low. It remains open to speculation as to whether there is a threshold size of tumour remnant that is safe to leave after surgery and which has minimal regrowth potential. At present, RT is usually administered to tumour remnants with supra- or extrasellar extension, and some advocate this approach for significant intrasellar tumour remnants.

A frequent approach used for small intrasellar tumour remnants (and empty sella) is a policy of observation with sequential MRI scanning to detect early evidence of tumour expansion. In the presence of tumour regrowth, RT is organised, and, because most NFAs are slow growing, most patients will avoid a second debulking operation. All patients with NFAs, irrespective of the administration of RT, require lifelong imaging because of the possibility of late regrowth(s).

\section{Types of pituitary radiotherapy; does radiosurgery have a role?}

Conventional fractionated external-beam RT concentrates an X-ray beam on a target volume (the whole fossa and any tumour extension beyond) by means of a crossfire technique involving several ports, each of which is directed at the target; the patient's head is immobilised in a tight-fitting mask. Supravoltage RT is given in daily doses of 200 cGy 4-5 times per week over a 5-6-week period up to a total dose of $4500-5000$ cGy $(4,36,57)$.

Radiosurgery is the precise stereotactic delivery (in a single session) of a high-radiation dose to a delimited target, with a sharp fall-off of radiation at the target margins. It allows delivery with a high degree of precision such that a necrotising dose is administered to the tumour with relatively little irradiation to 
surrounding tissues $(17,57,58)$. Such selective destruction of tumour is an attainable therapeutic goal because of great advances in diagnosis and imaging $(57,59)$.

Three forms of radiosurgery are available, as follows: proton-beam therapy using heavy charged particles (protons); gamma knife surgery using cobalt-60 gamma radiation-emitting sources focused on a specific fixed point; and linear acceleration (LINAC), which also uses photons and focuses on a stationary point but involves a moving gantry $(17,58-60)$. There are a number of published small series of outcomes following pituitary radiosurgery that have concentrated on small functioning pituitary tumours (59-64); the results have generally been disappointing. It does appear, however, that the time required to achieve a reduction in hormone secretion is significantly reduced following radiosurgery as opposed to conventional external-beam radiotherapy (65). Radiosurgery is a relatively new technique and the initial disappointing results may reflect relative user-inexperience. The periods of followup in these studies have also been rather short. There are few data relating to radiosurgery for NFAs, thus at present there is no accepted role for this treatment in the management of NFAs. In the future, however, radiosurgery may prove useful in treating tumours and tumour remnants that extend into the cavernous sinus, a site that is inaccessible to surgery.

\section{Conclusions}

All patients with NFAs require life-long follow-up imaging to detect evidence of tumour regrowth. Despite major advances in diagnostic and surgical techniques, the results of trans-sphenoidal surgery alone are poor. Postoperative tumour remnants have been shown to regrow in a significant proportion of patients, often many years after the initial surgery. RT is an important adjuvant treatment in the management of nonfunctioning pituitary tumours, which, when administered during the postoperative period, significantly reduces the chance of regrowth. Hypopituitarism is a frequent and significant complication of pituitary RT. Damage to the optic chiasm can be avoided by careful planning, dosing, and administration of the RT. Further data are required to evaluate more fully the risks of neurocognitive dysfunction in patients exposed to pituitary RT. Although there is no direct evidence for secondary intracranial tumour development following pituitary RT, there are insufficient data to report a conclusive relative risk for this potential complication.

Currently, there is no reliable indicator of tumour regrowth following surgery, though most centres advocate RT for large postoperative tumour remnants. Small, intrasellar, postoperative tumour remnants are often tracked by sequential MRI scanning and RT requested in the presence of tumour expansion. Ideally, an accurate and reliable means of predicting tumour behaviour in the postoperative period is required to allow targeted therapy for tumours with regrowth potential. In the absence of any clinical, radiological or pathological indicators of tumour regrowth potential, the most realistic expectation for the future lies with a novel molecular marker. Until such a test becomes available, efforts are being made to improve MRI surveillance to allow more accurate assessment of tumour volume with a view to quantitatively defining a 'safe' tumour remnant.

\section{References}

1 Gittoes NJ. Current perspectives on the pathogenesis of clinically non-functioning pituitary tumours. Journal of Endocrinology $1998157177-186$.

2 Melmed S. Pathogenesis of pituitary tumors. Endocrinology and Metabolism Clinics of North America 199928 1-12.

3 Shimon I \& Melmed S. Pituitary tumor pathogenesis. Journal of Clinical Endocrinology and Metabolism 199782 1675-1681.

4 Snyder PJ. Clinically nonfunctioning pituitary adenomas. Endocrinology and Metabolism Clinics of North America 199322 163-175.

5 Liuzzi A, Tassi V, Pirro MT, Zingrillo M, Ghiggi MR, Chiodini I et al. Nonfunctioning adenomas of the pituitary. Metabolism: Clinical and Experimental $1996 \mathbf{4 5} 80-82$.

6 Gittoes NJ, Bates AS, Tse W, Bullivant B, Sheppard MC, Clayton RN et al. Radiotherapy for non-functioning pituitary tumours. Clinical Endocrinology 199848 331-337.

7 Ciric I, Mikhael M, Stafford T, Lawson L \& Garces R. Transsphenoidal microsurgery of pituitary macroadenomas with long-term follow-up results. Journal of Neurosurgery 198359 395-401.

8 Ebersold M, Quasi L, Laws J, Sceithauer B \& Randall R. Long-term results in transsphenoidal removal of nonfunctioning pituitary adenomas. Journal of Neurosurgery $1986 \mathbf{6 4} 713-719$.

9 Chun M, Masko G \& Hetelekidis S. Radiotherapy in the treatment of pituitary adenomas. International Journal of Radiation Oncology, Biology, Physics 198815 305-309.

10 Grigsby P, Stokes S, Marls J \& Simpson J. Prognostic factors and results of radiotherapy alone in the management of pituitary adenoma. International Journal of Radiation Oncology, Biology, Physics 198815 1103-1110.

11 McCollough WM, Marcus R Jr, Rhoton A Jr, Ballinger WE \& Million RR. Long-term follow-up of radiotherapy for pituitary adenoma: the absence of late recurrence after greater than or equal to 4500-cGy. International Journal of Radiation Oncology, Biology, Physics $199121607-614$.

12 Comtois R, Beauregard H, Somma M, Serri O, Aris-Jilwan N \& Hardy J. The clinical and endocrine outcome to transsphenoidal microsurgery of nonsecreting pituitary adenomas. Cancer 1991 68 860-866.

13 Grant F. Surgical experience with tumours of the pituitary gland. Journal of the American Medical Association 1948136 668-672.

14 Emmanuel I. Symposium on pituitary tumours: (3) historical aspects of radiotherapy, present treatment technique, and results. Clinical Radiology 196617 154-160.

15 Ray R \& Patterson R. Surgical experience with chromophobe adenomas of the pituitary gland. Journal of Neurosurgery 197134 726-729.

16 Sheline G. Treatment of nonfunctioning adenomas of the pituitary. American Journal of Roentgenology 1974120 553-561.

17 Plowman PN. Pituitary adenoma radiotherapy - when, who and how? Clinical Endocrinology 199951 265-271.

18 Bradley K, Adams C, Potter C, Wheeler D, Anslow P \& Burke C. An audit of selected patients with non-functioning pituitary adenoma treated by transsphenoidal surgery without irradiation. Clinical Endocrinology $1994 \mathbf{4 1}$ 655-659. 
19 Turner HE, Stratton IM, Byrne JV, Adams CBT \& Wass JAH. Audit of selected patients with nonfunctioning pituitary adenoms treated without irradiation - a follow-up study. Clinical Endocrinology 199951 281-284.

20 Brada M, Rajan B, Traish D, Ashley S, Holmes-Sellors PJ, Nussey S et al. The long-term efficacy of conservative surgery and radiotherapy in the control of pituitary adenomas. Clinical Endocrinology 199338 571-578.

21 Littley MD, Shalet SM, Beardwell CG, Ahmed SR, Applegate G \& Sutton ML. Hypopituitarism following external radiotherapy for pituitary tumours in adults. Quarterly Journal of Medicine 1989 70 145-160.

22 Tsang RW, Brierley JD, Panzarella T, Gospodarowicz MK, Sutcliffe SB \& Simpson WJ. Radiation therapy for pituitary adenoma: treatment outcome and prognostic factors. International Journal of Radiation Oncology, Biology, Physics 1994 30 557-565.

23 Nelson P, Goodman M, Flickenger J, Richardson D \& Robinson A. Endocrine function in patients with large pituitary tumours treated with operative decompression and radiation therapy. Neurosurgery 198924 398-400.

24 Snyder P, Fowble B, Schatz N, Savino P \& Gennarelli T. Hypopituitarism following radiation therapy of pituitary adenomas. American Journal of Medicine $1986 \mathbf{8 1} 457-462$.

25 Al-Mefty O, Kersh J, Routh A \& Smith R. The long-term side effects of radiation therapy for benign brain tumours in adults. Journal of Neurosurgery 199073 502-512.

26 Tomlinson JW, Holden N, Hills RK, Wheatley K, Clayton RN, Bates AS et al. Association between premature mortality and hypopituitarism. Lancet 2001357 425-431.

27 Erfurth EM, Bulow B \& Hagmar LE. Is vascular mortality increased in hypopituitarism? Pituitary 20003 77-81.

28 Rosen $\mathrm{T} \&$ Bengtsson BA. Premature mortality due to cardiovascular disease in hypopituitarism. Lancet 1990336 285-288.

29 Bulow B, Hagmar L, Mikoczy Z, Nordstrom CH \& Erfurth EM. Increased cerebrovascular mortality in patients with hypopituitarism [see comments]. Clinical Endocrinology 199746 75-81.

30 Jones A. Radiation oncogenesis in relation to the treatment of pituitary tumours. Clinical Endocrinology 199135 379-397.

31 Brada M, Ford D, Ashley S, Bliss JM, Crowley S, Mason M et al. Risk of second brain tumour after conservative surgery and radiotherapy for pituitary adenoma. British Medical Journal 1992 304 1343-1346.

32 Bliss P, Kerr GR \& Gregor A. Incidence of second brain tumours after pituitary irradiation in Edinburgh 1962-1990. Clinical Oncology 19946 361-363.

33 Tsang RW, Laperriere NJ, Simpson WJ, Brierley J, Panzarella T \& Smyth HS. Glioma arising after radiation therapy for pituitary adenoma. A report of four patients and estimation of risk. Cancer 199372 2227-2233.

34 Popovic V, Damjanovic S, Micic D, Nesovic M, Djurovic M, Petakov M et al. Increased incidence of neoplasia in patients with pituitary adenomas. The Pituitary Study Group. Clinical Endocrinology 199849 441-445.

35 Jones A. Complications of radiotherapy for acromegaly. In Treating Acromegaly, pp 115-125. Ed J Wass. Bristol: Society for Endocrinology, 1994.

36 Sassolas G, Trouillas J, Treluyer C \& Perrin G. Management of nonfunctioning pituitary adenomas. Acta Endocrinologica 19931 $21-26$.

37 Tachibana O, Yamaguchi N, Yamashima T \& Yamashita J. Radiation necrosis of the optic chiasm, optic tract, hypothalamus, and upper pons after radiotherapy for pituitary adenoma, detected by gadolinium-enhanced, T1-weighted magnetic resonance imaging: case report. Neurosurgery 199027 640-643.

38 Kline LB, Kim JY \& Ceballos R. Radiation optic neuropathy. Ophthalmology 198592 1118-1126.

39 Atkinson AB, Allen IV, Gordon DS, Hadden DR, Maguire CJ, Trimble ER et al. Progressive visual failure in acromegaly following external pituitary irradiation. Clinical Endocrinology $197910469-479$.

40 Flickinger J, Nelson P, Martinez A, Deutsch M \& Taylor F. Radiotherapy of nonfunctional adenomas of the pituitary gland. Cancer 198963 2409-2414.

41 Zierhut D, Flentje M, Adolph J, Erdmann J, Raue F \& Wannenmacher M. External radiotherapy of pituitary adenomas. International Journal of Radiation Oncology, Biology, Physics 1995 33 307-314.

42 Rush S \& Cooper PR. Symptom resolution, tumor control, and side effects following postoperative radiotherapy for pituitary macroadenomas. International Journal of Radiation Oncology, Biology, Physics 199737 1031-1034.

43 Fisher BJ, Gaspar LE \& Noone B. Giant pituitary adenomas: role of radiotherapy. International Journal of Radiation Oncology, Biology, Physics 199325 677-681.

44 McCord MW, Buatti JM, Fennell EM, Mendenhall WM, Marcus RB Jr, Rhoton AL et al. Radiotherapy for pituitary adenoma: longterm outcome and sequelae. International Journal of Radiation Oncology, Biology, Physics 199739 437-444.

45 Breen P, Flickinger JC, Kondziolka D \& Martinez AJ. Radiotherapy for nonfunctional pituitary adenoma: analysis of long-term tumor control. Journal of Neurosurgery $1998 \mathbf{8 9}$ 933-938.

46 Rosen T, Wiren L, Wilhelmsen L, Wiklund I \& Bengtsson BA. Decreased psychological well-being in adult patients with growth hormone deficiency. Clinical Endocrinology 199440 111-116.

47 Peace KA, Orme SM, Thompson AR, Padayatty S, Ellis AW \& Belchetz PE. Cognitive dysfunction in patients treated for pituitary tumours. Journal of Clinical and Experimental Neuropsychology $1997191-6$.

48 Peace KA, Orme SM, Sebastian JP, Thompson AR, Barnes S, Ellis A et al. The effect of treatment variables on mood and social adjustment in adult patients with pituitary disease. Clinical Endocrinology 199746 445-450.

49 Lillehei KO, Kirschman DL, Kleinschmidt-DeMasters BK \& Ridgway EC. Reassessment of the role of radiation therapy in the treatment of endocrine-inactive pituitary macroadenomas. Neurosurgery 199843 432-439.

50 Giannattasio G \& Bassetti M. Human pituitary adenomas. Recent advances in morphological studies. Journal of Endocrinological Investigation 199013 435-454.

51 Levy A, Hall L, Yeudall WA \& Lightman SL. p53 gene mutations in pituitary adenomas: rare events. Clinical Endocrinology 1994 41 809-814.

52 Knosp E, Kitz K \& Perneczky A. Proliferation activity in pituitary adenomas: measurement by monoclonal antibody Ki-67. Neurosurgery 198925 927-930.

53 Hsu DW, Hakim F \& Biller BMK. Significance of proliferating cell nuclear antigen index in predicting pituitary adenoma recurrence. Journal of Neurosurgery $1993 \mathbf{7 8} 753-761$.

54 Bates A, Farrell W, Bicknell E, McNicol A, Talbots A, Broome J et al. Allelic deletion in pituitary adenomas reflects aggressive biological activity and has potential value as a prognostic marker. Journal of Clinical Endocrinology and Metabolism 199782 818-824.

55 Gittoes NJ, McCabe CJ, Sheppard MC \& Franklyn JA. Retinoid X receptor gamma mRNA expression is reduced in recurrent nonfunctioning pituitary adenomas. Clinical Endocrinology $1998 \mathbf{4 8}$ 527.

56 Zhang X, Horwitz GA, Heaney AP, Nakashima M, Prezant TR, Bronstein MD et al. Pituitary tumor transforming gene (PTTG) expression in pituitary adenomas. Journal of Clinical Endocrinology and Metabolism $1999 \mathbf{8 4} 761-767$.

57 Jackson IM \& Noren G. Gamma knife radiosurgery for pituitary tumours. Best Practice and Research in Clinical Endocrinology and Metabolism 199913 461-469.

58 Laws ER Jr \& Vance ML. Radiosurgery for pituitary tumors and craniopharyngiomas. Neurosurgery Clinics of North America 1999 $10327-336$

59 Thoren M, Rahn T, Guo WY \& Werner S. Stereotactic radiosurgery with the cobalt-60 gamma unit in the treatment of 
growth hormone-producing pituitary tumors. Neurosurgery $199129663-668$.

60 Degerblad M, Rahn T, Bergstrand G \& Thoren M. Long-term results of stereotactic radiosurgery to the pituitary gland in Cushing's disease. Acta Endocrinologica 1986112 310-314.

61 Pollock BE, Kondziolka D, Lunsford LD \& Flickinger JC. Stereotactic radiosurgery for pituitary adenomas: imaging, visual and endocrine results. Acta Neurochirurgica - Supplementum 199462 $33-38$.

62 Yoon SC, Suh TS, Jang HS, Chung SM, Kim YS, Ryu MR et al. Clinical results of 24 pituitary macroadenomas with linac-based stereotactic radiosurgery. International Journal of Radiation Oncology, Biology, Physics $1998 \mathbf{4 1}$ 849-853.

63 Voges J, Sturm V, Deuss U, Traud C, Treuer H, Schlegel W. et al. INAC-radiosurgery (LINAC-RS) in pituitary adenomas: preliminary results. Acta Neurochirurgica - Supplementum 199665 41-43.

64 Park YG, Chang JW, Kim EY \& Chung SS. Gamma knife surgery in pituitary microadenomas. Yonsei Medical Journal 199637 $165-173$.
65 Landolt AM, Haller D, Lomax N, Scheib S, Schubiger O, Siegfried J et al. Stereotactic radiosurgery for recurrent surgically treated acromegaly: comparison with fractionated radiotherapy. Journal of Neurosurgery $1998 \mathbf{8 8} 1002-1008$.

66 Bates AS, Van't Hoff W, Jones PJ \& Clayton RN. The effect of hypopituitarism on life expectancy. Journal of Clinical Endocrinology and Metabolism 199681 1169-1172.

67 Bates AS, Bullivant B, Sheppard MC \& Stewart PM. Life expectancy following surgery for pituitary tumours. Clinical Endocrinology 199950 315-319.

Received 28 November 2000

Accepted 7 March 2001 